\title{
MIND AND MEDIUM IN ART'. (III.)
}

\author{
By HENRY J. WATT.
}

As in so many of the general problems of art it is important to coördinate discussion that springs chiefly from the arts of vision with their less substantial sister. In music, at first glance, we might be tempted to say there are no tools and materials. The composer records his inspirations upon paper with a view to legibility only. He elaborates in imagination the effect he desires, and restricts his record to the minimum required by the performer for adequate reproduction. The performer in turn must be able to imagine from this record, at least approximately, the effect intended, and he will then be able to produce that effect for others on his instrument, voice, violin, piano, etc. He may in some cases be able to enjoy it completely apart from any real instrumental performance. But this power clearly presupposes very perfect acquaintance with the sounds produced by a performer on the instrument for such a record. Hence clearly the musical instrument is a necessary medium in the progress from composer to enjoyer. So instruments are the materials of music. Perhaps the performer might be held to be the tool. But there is no value in carrying the analogy into such detail.

The instrument has long been recognised as an important condition of 'style'2 in music. The human voice is a very special instrument with its own great virtues and limitations; it cannot be treated by a composer as if it had the freedom and range of a violin or organ, or as if it were devoid of that marvellous power of changing its timbre from instant to instant at the behest of the singer, a power lacking (? almost) entirely in the piano and only imperfectly attained in the organ at enormous expense. Orchestral works can be studied at the piano, but they must be heard or imagined in the orchestra. Berlioz-great genius of orchestration-relates with scorn how in his contest for the Prix de Rome he was required to produce a work for voice and orchestra which was judged by reproduction on the piano, while the winning work was properly

1 A contribution to the Symposium presented at the Congress of Philosophy in Oxford, 24-27 September, 1920.

${ }^{2}$ Cf. Sir Hubert Parry's Slyle in Musical Art. London, 1911. 
heard only after judgment had been given ("par des gens qui ne sont pas musicieus." ${ }^{\prime}$. All this is probably commonplace amongst musicians.

Would it were so amongst the great public and the performers who meet their taste! Every other virtuoso regales us with Wagner's Pilgrims' Choris on the piano, an instrument in which that work produces only a farcical effect. Just beeause it is designed for the orchestra, it is obviously difficult to play on the piano and so, in those for whom essential beauty is a secondary or remote consideration, it excites wonder and applause. The translation is as appropriate as would be the embodiment of Laokoon in glass or straw. To write piano pieces round the melodies of Schubert's loveliest songs, as Liszt did, shows an equal lack of taste. Anyone who really knows and appreciates the song could only be bored and disgusted with the piano's feeble echoes of the rapture of "Hark, Hark. the lark," or the tempestuous terrors of the Erlking.

And it is quite easy to account for the characteristic style of each instrument. The organ has always been and must ever remain a somewhat lethargic instrument incapable of producing intensive stresses. But it gives sustained tones of great variety. So the composer has perforce to build his works with tones of certain intensive, temporal, and colour values. The bricks and mortar of piano works are very sharp and short, but intensively malleable with a rather limited and mysterious range of colour. The violin has almost complete freedom in action, sustenance, stress, and colour. These things are familiar and need only be briefly recalled.

Let us now turn to Mr Marriott's thesis, which seems kin to the thoughts of Semper and others ${ }^{2}$. Are practical and technical reasons the same thing as aesthetic reasons? The answer cannot be a simple yes or no. We must distinguish two aesthetic processes-aesthesis, or act of enjoyment, and judgment thereon. Judgment we may at once put in its place. It is always cognitive; it always implies a conceptual apprehension of the objects, predicates and relations involved in it, whether these objects be things, sensations, or mere subsistents, and whatever the predicates and relations may be. The aesthesis is not so easily placed. It is of course always an act involving a 'relation' or unifying process of experience. It cannot be mere sensation for example; for then it would be indistinguishable from the sensory datid of cognition or of instinctive action. Nor can it be merely subjective, as if the objective

- "N'esti-il pas évidont que le piano, anéantissant tous les effets d'instrumentation, nivelle, par cela seul, tous les compositeurs?" Mémoires, vol. т. chap. 22.

2 Cf. E. Meumann, A ssthetik der Gegenvart, Leipzig, 1912, $125 \mathrm{ff}$. 
counterpart of it were irrelevant, i.e. the tones, colours, forms, of the beautiful object. Beauty cannot be skimmed off all its actual forms in a pure essence in which they play no part. Beauty like knowledge always attaches to some object.

The analogy of knowledge might tempt us to suppose that there is a 'logic' of beauty, shall we say "intuition expressing itself," as there is a science of the pure concept and its relations ${ }^{1}$. It is quite legitimate to make abstraction of the forms and laws of any range of cognitive processes from their (integrative) basis, as logic abstracts from the basis of any meaning in my mind or yours at one and another moment. But that need not lead us to suppose that logic is completely independent of knowledge and psychology. We must land ourselves, as the greatest have done, in a philosophical cul de sac if we do not realise that all knowledge is one great system in which the highest grows continuously out of the lowest. The crown is not arbitrarily placed upon the head of sense or assumed by it. The kingship is inherent.

In beauty we shall hardly find a parallel to this. There must always be an act of grace or marriage between the objective and subjective in beauty, a marriage of true minds, born for one another and finding each other's nature predisposed for harmony. We have to discover the secret being of this harmony that is the relation between subjective and objective mind. Namely, what is that rhythm of interaction between tones in all their variety, groupings, and sequences, between colours, forms, and motions, between smells, tastes and other limited resources of the simpler senses, on the one hand, and the pulses, acceptances, anticipations, appetites of the subjective mind, on the other, that appears or is for us pleasure? How shall we describe the collisions, refusals, divagations, and distresses between these two streams of actions that is displeasure? A pure science of these things is hardly yet in existence. Until it has been fully and intimately grounded in the detail of knowledge, I do not see what value such formulas as the "expression of intuition" can have. These terms are so vague and general and their whole atmosphere is so inimical to the detail without which general propositions (except in logic) dare not be advanced, that they can only be set down as anti-science and obscurantism.

Having thus divided the aesthesis into three parts, we may notice that our knowledge of the subjective side is exceedingly vague and schematic. Our knowledge of the 'relation' that is pleasure-displeasure

1 This is the thesis towards which Mr Walkley inclines, though I am not at all sure that he really means it to be taken in so extreme a form. 
is equally feeble. The objective side alone is open to inspection with moderate ease. But even here there is great controversy. What especially is included in this objective field? A great wave of opinion has drenched us with the dogma that only sensory data and complexes are admissible. Away with all 'subject' and association! No perceptual, reminiscent, associative, literary, anecdotal, thematic adhesions are to be tolerated in any art (scilicet visual art). Colours, forms, times, spaces (indicated), - these and the like alone are fit elements of a work of art.

But there is a good deal of perversity in this dogma in spite of the earnestness and desperation with which it has been preached. For music has within the same period been striving to attain the very opposite goal, namely to force upon its medium perceptual adhesions that can hardly be induced even to cast a shadow in the desired direction. This is another thing that makes it so important always to compare the visual and auditory arts. They are so differently constituted that they are nearly always trying to do opposite things. Vision gets tired of being representative and tries to be as directly divine as music, which at the very moment aspires after more and more contact with the things of earth. Vision longs to be rhythmical while music wooes the rhythmic freedom of adagio $^{1}$ and might even yet become a new unmeasured music. Vision makes frantic efforts after a pure harmony of colour, when music tries to shake out of itself the last traces of modulated sweetness in order to be more characteristic of things that are not so clearly inherent in its nature. Of course it is well to create an art of characteristic noise, and it may even thrill our being; but it no more affects the course of music that has been building itself up in a steady progress through the centuries than the beauties of prose annul and negate the much older and still potent charms of poetry.

So we may pass over the attempt to create a dogma of limitation. The arts of vision in the greatest creators have known no limitation to the purely sensuous range of data. They have always freely admitted whatever furthered their virtues, felt as these are in the immediate poignancy of the aesthesis. In the Winged Victory, the Laokoon, the Creation of Adam, the Last Judgment- there is much more that is of the greatest aesthetic force than ever the mere eye can see.

1 "Hier steht nun das Adagio dem Allegro gegenüber, wie der gehaltene Ton der figurierten Bewegung. Dem Tempo adagio giebt der gehaltene Ton das Gesetz; hier zerfliesst der Rhythmus in das sich selbst angehörende, sich allein genügende reine Tonleben....Was im Allegro der Wechsel der Figuration ausdrückte, sagt sich hier durch die unendliche Mannigfältigkeit des flektierten Tones." Wagner's Gesammelte Schriften, Leipzig, 1907, v1. 284. 
But the difficulty is to show how these perceptual moments link up with the purely sensory data to form the objective stuff of art; we think of course that we understand all this perfectly, simply because we know which colours to put together, which tones to group and to serialise. As one of my critics tells me, and as many others think, "The rest may reason and welcome; 'tis we musicians know." But they do not know. Nor do the colourists know why one colour, one form, one space goes with another. Guesses can be made and some accord fairly with the little direct psychological knowledge there is. But we are far from the needful pure science of these things. So long as this is so, what right has anyone to say (in the face of the practice of the great masters) that perceptual processes do not belong properly to the objective stuff of art? Of course I should not dispute the fact that some subjects are tawdry and dangerous, and great regions of non-perceptual art in vision may still lie unexplored. For a medium sets limits and in doing so it opens up channels closed to other media. The question concerns the canons of art only.

The difficulties of the problem may be exposed in another way. Colours, forms, tones and their groupings, etc., may obviously be beautiful. But, tell us, can a subject possibly be beautiful? Frankly, is it conceivable that a thought, an idea, a perceptual substance-unity (the orange without the colour, shape, smell, weight, etc.--what is left over), or an association, can be beautiful, schön ('shining')? Never! Hence let subject be for ever banned from art (and dragged into music).

Let us answer this by a counter-question. Why are colours and forms beautiful? Because they 'shine' and grip the eye, sending a thrill into the soul through a pore of that sense, as it were? Beauty streaming to you straight from the canvas and labelled such from its very start? Surely not. Tones are not felt to be 'out there' at the piano, in the singer's throat: they are everywhere, nowhere; they do not 'shine'; they merely blend with one another in your being so that you think they and your soul are one (or some other such vagueness). In fact, again, we know next to nothing of the basis of these sensuous delights. And as we succeed in laying bare their nature, they seem strangely to evaporate into things that look like relations, clearness of sequence, repetitions, variations, and echoes, that all seem so like those things with which only the conceptual intellect can deal adequately. But this last conclusion would be very wrong indeed. They are clearnesses and distinctnesses and recurrences of sensory stuff that strike and thrill our subjective mind to its responses. They are not conceptual relations of the 
intellect. This is a mistake made by most prominent thinkers about art. It has led one of them recently to assert more or less definitely that a person who does not know all that is going on in a musical work, the tones, intervals, chords, keys, modulations, reminiscences, etc., can no more properly enjoy it than he could enjoy poetry in an unknown tongue ${ }^{1}$. That I am persuaded is quite wrong, untrue to the great and spontaneous joy that the greatest art gives even to the inexperienced provided they are 'pure in heart.' One could hardly dispute that the trained and swiftly judging mind must reap the greater and fuller joy from the art. But the germ of enjoyment is untutored. If it were not so, no intellect could bring it to birth.

If, then, we do not know in detail the roots of beauty in colours and forms, how may we deny that beauty can also spring from perceptual, conceptual, memorial and even emotional constructions? We simply cannot.

But it seems perfectly clear and certain that without a basis of sensory beauty there can be no work of art. Pure intuition or no, a* work of art must be created, it must be embodied. And beauty must permeate its whole being, sensory, perceptual, imaginative, from whichever end of the series its soul may spring.

We may now return to the problem of discussion. That now takes form in the question -are there any limits in art to the range of perceptual and other adhesions to the sensory basis of the work? Do these adhesions include such as are concerned with the medium and its characteristic manipulation? Or does the range of the latter out-reach the former? For, of course, it is out of the question that actual matter and its manipulations could bodily enter the aesthetic object,

1 C. Stumpf, "Die Attribute der Gesichtsempfindungen," Abh. d. preuss. Ak. Wiss. 1917, vII. 56 f. "Wie dagegen ein wahrhaft künstlerischer, verstehender Genuss unserer harmonischen und polyphonen Musik ohne jede Zerlegung, jede Beachtung des selbständigen Ganges der Stimmen möglich sein soll, wäre schlechterdings nicht einzusehen. Dabei wollen wir gar nicht bestreiten dass auch ein Dahinströmen ganz unzerlegter Klangmassen durch das Auf- und Absteigen des Ganzen und durch den Wechsel der Klangfärbung und der Zeit. und Stärkeabstufungen gewisse 'musikalische' Stimmungen hervorrufen kann. Der Geniessende mag dabei der Musik gegenüberstehen wie etwa den Farben der Kalospinthechromokrene oder wie einer ihm zwar unverständlichen aber mit Effect gesprochenen Rede." My analysis of the primarily melodic functions of music shows that this account is far from the whole truth of the 'natural' apprehension of music. An exact parallel to this applied to the 'natural' enjoyment of a picture or of dancing would surely be ridiculous. Debussy on the other hand dreads in the auditor a knowledge of means. Does not this cast some doubt upon their dignity? 
which is always as apprehended and known, i.e. essentially mental or spiritual, as Mr Walkley properly recalls. The sole question is,--are these perceptual and cognitive attachments irrelevant to the scope of the aesthesis or are they not? And my answer is,--they are not and never can be irrelevant in good art, i.e. quâa in a good spectator. But on the other hand there is no means of fixing a norm for the extent of them that a good spectator shall have at his disposal. That is simply another form of the truth often so crudely distorted that powers and therefore tastes differ. The judgments by which they express themselves cannot be disputed any more than can any other facts; but their basis and general validity can be discussed.

We are now merely repeating what was noted above that the spectator brings his mind and all its sensibilities into the aesthesis. Much of this mind, namely the perceptual, associative, conceptual 'forms' that apply themselves to the sensory stuff offered, become simply continuous therewith and form the objective mind of the aesthesis. The rest of the mind's dispositions are free to respond to this presentative complex and to play with it until its interest is exhausted. You cannot show marble, bronze or wood to a human eye without its perceiving the material and thinking about it in some way or another. Whatever thus accrues to the aesthetic moment must either favour or hinder the aesthesis. Being intimately bound up with its objective part, these adhesions cannot remain indifferent to it. They will either agree with the colours, forms, and manipulated textures of the bronze, or contrast with them. Some minds are pleased by contrast; it arouses their wonder and astonishment. Perhaps this motive makes an appeal in the choicest circles more frequently than is commonly supposed. Has not a notable composer of ours ${ }^{1}$ declared that novelty is the essence of the beautiful? Does not the present age of strenuous inspiration try desperately to produce wondrous effects, using devices that many of the previous masters may well have rejected in principle? But of course this makes a much more artful wonder than the bottled schooner in full sail or than the veiled figure in an ivory piece. The main trend of the beautiful seems, however, to keep aloof from this fringe of the marvellous in mere technique. No doubt a great deal of pure joy can be got from a sense and knowledge of

1 Cyril Scott, Philosophy of Modernism in relation to Music, p. 3: "In order to create something beautiful, one must create something new." Mr Scott chooses a mid-way ("Romanticism-nowness within limits") between classicism and futurism and in a certain sense his statement is a truism. But it is surely strained to imply, as his examples suggest, that the newness that is beauty should always reside in some general feature or style of work. 
the nice operations in a work of art. But surely the first ground of the aesthesis in sense must be the natural sensuous coherences themselves of colours, tones, forms, and motions. And from this ground progress towards ideas and emotions should in the main be direct, not swerving far aside into special perceptual tracks, unless it intends thereby to return to the final reaches of mind with greater force and appeal. Nothing can of course prevent the normal range of perceptual and other associates appearing, while greater experience in art will inevitably refine and extend this range in special directions. Thus a work must appeal differently to the tyro and to the expert. And there must be a world of artistic objects for all grades of experience. Are we not nowadays learning to 'appreciate' the art of the negro, the primitive, and the peasant? Thus art must always allow for and largely first build upon the normal contents of mind and memory.

And it is perhaps one of art's most telling devices to appeal to mind by some special deviation from the currents and expectations of the normal mind. In this sense it may be true that novelty is the essence of art. I would rather say that the purpose of the novelty is to direct the mind of the spectator into a special direction. But this device will hardly extend to the usage of the medium of art in ways that are unnatural.

In summary we may say that the objective aspect of art cannot be limited to strictly sensuous data. It must be extended to include any 'objective' that is adequately founded upon these data. Hence the largely conceptual arts of literature. The spectator's awareness of all that pertains to the material of art and its manipulations thus comes within its scope. But I fail to see how one could reasonably hold that of all the non-sensuous objectives of art only those appertaining to the material and its manipulations should be admitted. Zeal for an important and perhaps neglected part may blind one to the rest, just as one's contempt for a greatly exaggerated value (e.g. of subject) may lead one to depreciate it unreasonably. The field of art is the whole soul and its congruences, - and its conflicts, too, its dissonances as well as its consonances (provided we can use them 'paraphonically'). It is the extreme sweetness of many subjects that has made subject such taboo. Great skill is needed to make art of these pretty ('easy') beauties. The discords of life that also appeal so strongly to our emotions need similar skill of treatment. And just as music gains more perhaps from the progressive conquest of dissonances, so the greatest wealth of the arts of 
subject has probably always lain on the side of the dramatic and tragic and less than pretty. But in the sphere of the perceptual associates of the medium of art, there seems to be no analogue of this; we do not see great artists growing more artful in the false, perverted, and imitative use of materials and tools, nor does the art seem to flourish that scorns technique, perverts good form and flouts good taste for no artistic end but merely for the love of novelty.

Music is comparatively free from these remoter influences of tools and materials. In the visual arts perceptual associates can be involved that are not at all visible but merely known, as one knows that the arms of a marble cross bear great strain, which again one knows is a natural virtue of any sort of wood, even of a tree branch. In music probably every aspect of the instrument that is artistically relevant is actually heard, as the grain of wood and marble is seen. Do we ever genuinely find a work the lovelier, the better its style suits the mere instrument, as Chopin's music suits the piano? Is it not enough to say that his music suits the tones that are typically produced by piano action? An auditor does not seem greatly urged to go beyond the heard sound and its typical characters to the thing that produces them. He may have special interest in instruments and he may know them by their tone. The different trade types of piano differ greatly in their timbre, but even acoustic specialists could hardly say at all precisely why they differ and no aesthetic listener probably takes any thought of the point of hammer blow into his aesthetic moment. And yet this is clearly a matter of the characteristic use of an instrument. I think one may take it that the finest violin music may be completely enjoyed without any thought of the material, manufacture, technique, and environment of origin, of the performer's violin. So although there is a vàst amount of the greatest interest to be known about instruments in relation to music, I doubt whether it has any necessary aesthetic value whatever.

But perhaps we do wrong to mention the instrument in this connexion. We might rather think of the performer's vital, beauty-expressing movements than of the mere mechanism that carries them to the sounding strings. Should we have thoughts of Pachmann's finger-action and pedalling in order fully to savour the beauty of his touch? Must we first know how to play the big drum and cymbals, the bassoon and viola, ere we can hope to exhaust the loveliness of a symphony, and must we think of the playing of every instrument while we listen? Surely not. Such considerations are probably of little influence in music; certainly far less so than in the visual arts. Tones in a sense are divorced from 
material and are not shaped even by the tools that physically determine them. They are entities of independent being, divine as folks say, again.

But in thus discarding the most of the perceptual and memorial associations of music and its instruments and performers from co-operation with the aesthesis, I would not be thought to set up any limits in this respect. Such limits cannot be set up in the visual arts where association is more direct and powerful. It is not necessary to have any fixed stock of technical thoughts, but everyone has many of these and they are naturally prominent and influential. In music such thoughts also exist, but they are not naturally responsive and influential during aesthesis.

Finally, I think a protest should be made against the attempt to turn art into a kind of utilitarian practice. Art may well have originated in the useful crafts and it has something in common with the gestures and expressions that are of social utility. But just as the study of mind from the biological side has in the primates had to recognise beyond hunger, love and play a delight in mere sensuous or intellectual effects, as when a monkey plucks at a vibrating pin or a child beats a drum indefinitely, so the science of art must rise above the biological cant that was natural in a recent generation and restore even to popular favour the idea that art is one of the three supreme ends of the spirit, a delight in congruous (true, good) being. After all biology now proclaims loudly that an organ is first formed and then, may be, finds a use (the world has not much time to waste on useless things). Well, then, art and knowledge and morality have first been formed and have been put out on loan. No amount of use or habit-craft and no amount of mere 'need' would ever have brought them into being. And so no matter out of what actions or organs they arise and no matter how they are used, they are values essentially independent of these attachments. $\mathrm{Mr}$ Marriott's maxim can only be true if he means by characteristic just aesthetic. If, however, he means to suggest that what is in some sense objectively characteristic is found by us to be also aesthetic, does he not go far to show how the values of art may be objectively or really grounded and permanent, as knowledge is?

It may be the recognition of this that has drawn $\mathrm{Mr}$ Walkley towards the nerveless abstractions that Croce puts in the place of the theory of art. Although knowledge and beauty are unique phases of the spirit, they must be used by the mind as a whole. The new essence they bring to birth is not degraded in the least by any interaction with the other 
level of mind. It must surely be evident that things cannot be taken out of the personality or imagination or intuition of an artist and embodied in sights, sounds, or motions, unless these vessels can contain them. Here we come upon the majestic truth that "I and my Father," the work of art and the artist's 'personality' to that extent are one and yet so completely two. 